\title{
An Assessment of Retention Strategies on Performance Among National Police Service Officers: A Case of Kisumu County, Kenya
}

\author{
Nixon Makokha \\ Department of Security and Correctional Science \\ Kenyatta University \\ Dr. Bernard Munyao Muiya \\ Department of Security and Correctional Science \\ Kenyatta University
}

\begin{abstract}
Organizations are ever competing to retain their best performing employees and as such, this has become a significant challenge facing security agencies. The police service has to ensure maintenance of the law enforcement workforce level. Human resource departments in the police service therefore need to motivate and retain its most talented employees as a result of the dynamics in the workforce. The government of Kenya has carried out several reforms like putting up new housing units, leasing of motor vehicles and merging Police units with a view of keeping and retaining the most talented officers. However, police officers are still leaving for other organizations. This study did an assessment of retention strategies on performance of the National Police Service officers in Kisumu County, Kenya. The objective of the study was to investigate how training and development strategies affect performance of the National Police Service officers in Kenya. The study was structured by Fredrick Herzberg's Two Factor Theory and Job Embeddedness theory. The study adapted a mixed methods approach by combining cross-sectional survey design and phenomenology design. Data from a sample of 108 officers was collected through a self-administered questionnaire and a key informant guide. Both NonProbabilistic and Probabilistic Sampling methods were used. Thematic data analysis was employed in analyzing qualitative data while descriptive method was used to analyse quantitative data. The results revealed that training and development had a statistically significant influence on performance of the national Police Service The study recommends adoption of organizational learning in the police service, particularly for junior officers. The National Police Service should formulate policies and strategies to mitigate the high labour turnover within the service.
\end{abstract}

Keywords: Retention, Strategies, Training, Development, Performance, Police

DOI: $10.7176 / \mathrm{PPAR} / 11-5-06$

Publication date: June $30^{\text {th }} 2021$

\subsection{Background of the Study}

According to McKnight, Phillips, and Hardgrave (2009) a significant challenge facing security agencies is maintenance of the law enforcement workforce level. As a result of the technological advancement, increased globalization and awareness, police officers globally should pay more attention to the increasing social disorders. Police officers mandate is widening everyday surpassing the element of mere law enforcement to include some militaristic mandates and gathering of intelligence, counterterrorism and immigration administration. Further, the law enforcement organizations have to strive towards a reliable and efficient performance of their duties, in the aspect of growing the policing range of duties as well as the dwindling resources.

Policing has turned out to be knowledge oriented, as a result of adoption of community-oriented approaches and thus manpower has become an asset which is resourceful and you cannot be wished away for a law enforcement organization to succeed. Organizations are ever competing to retain their best performing employees and (Fox , Byrne, \& Roualt, 2009) note that the police are not exceptional. Human resource departments in the Police, therefore need to motivate and retain its most talented employees as well. Previously, the human capital management in Police service used to be given less attention but dynamics in the workforce has prompted the management to pay more attention to it. The new development in human capital management has resulted to better performance, overall organization survival and productivity (Fox, et al., 2009).

The number of officers leaving the service prematurely continues to grow in significant numbers hence putting to doubt the future of police profession (McKnight, Philips \& Hardgrave, 2009). Less career and organizational commitment of police officers is turning out to be of great concern since it is usually perceived as a precursor to the resolution of officers willing to exit from their employment. To get better output from law enforcement agents, policing department should come up with ways of ensuring employees do not leave their careers prematurely. In order to improve employees' productivity, police administration should come up with 
strategies which are geared towards retaining their employees. Orrick (2008) noted that high rates of turnover are associated with deplorable working environment, less likelihood of career growth, inadequate compensation package and dissatisfaction of employees causing department myriads of challenges.

High labor turnover demoralizes employees resulting to reduced productivity which in turn impacts negatively to the organization's output. Hence it is imperative for organizations to implement and formulate practices of employee policies and practices; to not only retain the staff in an organization for long but also to ensure they are motivated thus improving their performance. Succession, retention, development, placement, recruitment and selection are vital while managing the employees since competitive advantage can be suitably created through organizational employee value addition (Mellahi \& Collings, 2010). Organization's progress is wholesomely linked to performance of employees.

General preferences have also been found to be a determinant in retention with the youthful employees being less committed to the organization. This makes majority of them to change careers frequently in comparison to the rest of employees in a bid to secure better paying employments (Mellahi \& Collings, 2010). An exit of officers is a major test in police career. In United States, power is moving from employers to employees due to poor retention strategies. Employees can be satisfied and retained within those organizations which invested heavily on both the intrinsic and extrinsic job satisfaction determinants such as salary appraisal, job promotion among other career advancement programmes. Mendez and Stander (2011) in their study in United Kingdom showed that employee retention is a process which is key for the performance of the organization to remain competitive. He notes that career development, job rotation and proper leadership as factors that promote high retention rates within any given organization. He advocated for human capital approach in order to improve employee retention rates. Hence, for the organizations to uphold their competitive advantage, they require staff with commitment and well skilled for the job.

The National Police Service (NPS) of Kenya, Article 244 of the Constitution states that its members aim to achieve a high degree of professionalism and discipline, to promote accountability and to train the personnel to the highest standards of competence. Moreover, honesty and respect for constitutional norms in the defense of basic liberties and human rights and in the promotion of larger society relations. This demonstrates that the NPS's key aim is to implement staff retention measures. The NPS consists of eight directions with human resource operations and workforce management or involvement in the Directorate for Human Capital Development. The directorate's main duties include human resources selection and recruiting, management of employees, training and development, performance management, career management and worker wellness, such as sports.

The Directorate ensures adequate selection, training, compensation, evaluation and management of personnel. One of the main duties, such as the human resources management mandate of the police force, was taken over by the National Police Service Commission (NPSC). The NPSC's creation is especially to monitor the human resources functions of the NPS as established in both the Constitution and the conclusions of the different Task Forces designated by the state on the policing duty to uphold law, order as well as security. It's difficult to keep NPS retention rates high. According to the Ransely Task Force Report from 2009, the majority of police officers were leaving because of low motivation, dissatisfaction, policing bureaucracy, job pressure, and policing stress. As a result, the purpose of this research was to see how retention methods impact NPS officer performance in Kisumu County.

\subsection{Statement of the Problem}

Exodus of law enforcement officers in Kenya has reached an alarming rate. This has been attributed to unfavorable working condition and unconducive work practices (Ransley, 2009). In order to better the welfare of officers and translate the service into a professional and respectable institution, the state started on reforms after the promulgation of the new Constitution in 2011. Before then, several task forces had come up with a raft of recommendations that were to be implemented in the reform's agenda especially the Ransley 2009 report. To check on the mass exodus of skilled officers from the service, the NPSC was brought on board to look at Human resource issues. However, the expected reform measures are well behind the schedule and mostly the anticipated changes are yet to be experienced. (Policing Accountability Report, 2014).

There have been efforts to improve the terms of job for the law enforcement agents including leasing vehicles, group life cover and better housing. However, these investments are yet to translate into the best strategies to check retention within the service (Audit Report on Police Reforms, 2015). Inadequate management and retention policies in an institution leads to job displeasure which leads officers to leave the service in search of better jobs. A study conducted in 2017 indicated that the NPS lost approximately $7.5 \%$ of its officers from 43,256 in 2015 to 40,501 in the year 2016. The reduction was as a result of retirement, death in line of duty, natural attrition and sackings. This survey seeks to assess how retention strategies affect performance among NPS officers in Kenya, with specific focus on the nexus between training and development and performance of officers in the National Police Service. 


\subsection{Objectives of the study}

To investigate how training and development strategies impact performance of the NPS officers in Kenya.

\subsection{Research Questions}

How does training and development strategies affect performance of NPS officers in Kenya?

\subsection{Empirical Review}

This section reviews empirical literature related to the study objectives

\subsubsection{Training and Development}

Training and career development among employees are regarded to be important aspect in ensuring employees do not exit the organization. Organization invests in training their employees to the best possible standards expecting commensurate improvement in performance. Clark, (2001) noted that organizations are engaging in development through analysis of proficiency, input on the interests of the employees, development of needs and evaluation of multisource competencies then come up with what needs to be done. Leblebici (2012) recommended that organization and individual employees should always seek to improve their skills and competencies by continuous investment in training. It is mostly the initiative of the employer to start training programme which align with the requirements of the job. Employees always feel that they have something to offer in terms of their expertise which they apply in their careers and use to share with other workers.

Training is crucial in most sections of the police service though the environment today seems to be debatable (Birzer, 2003). Training boosts the skills and capacity of the police and increase the chances of the officer winning the confrontations which in turn reduces complaints and lawsuits against the department or individual police officer. Community also gains more confidence with the police service when officers undergo trainings. The trainings endeavor not only in skills of apprehending the criminals but also in the daily challenges of police officer. When there are budgetary constraints, training is mostly among the first casualty in the reduction of funding (Leighn, 2002). The success of development in Kenya including attainment of vision 2030 is highly dependent on peaceful coexistence of the people which on the other hand relies on the level of security in the country. It is the business of the NPS to provide security which is of quality to the general public in Kenya by greatly observing the rule of law and promoting strong community collaboration in all aspects of life.

Training and development were outstanding among the proposals which Ransley's Task Force (2009) fronted for consideration in police service in Kenya. Although the senior officers have been receiving reasonably good and frequent training, this has not been replicated to the lower cadre of officers. As a result of the government decision to do away with police officers' national integration, the NPS has hitherto remained in a state which is Balkanized (Greenhaus, 2004). In a study by Jagero, Komba, and Mlingi (2012) which sought to find a connection between job training and the performance of workers of courier corporations in Tanzania, it found existence of a link between the two. An inquiry by Ngari (2015) established that on-the-job training affects production by improving the levels of the skills, performance and affects the satisfaction of the customers positively. Ahmad , Iqbal, Mir, Haider, and Hamad (2014) and Khokhar, Laghari, and Lakhani ( 2019) reported that on-the-job training increases the effectiveness of employees. In a research conducted by Tukunimulogo (2016) in Mumias Sugar Company limited, Kenya, it was reported that the on-job-training strategies are likely to promote more employer potential than without.

\subsection{Theoretical Framework}

Herzberg's two-factor theory and job embeddedness theory supplied the basis for this research. These two ideas were utilized to frame and guide the study, with the understanding that employee motivation is critical to any organization's success. Considered in its entirety, employee motivation is that level of commitment and innovation that staff of an organization hold during their working hours. If the level of commitment diminishes, there is a likelihood that employee productivity reduces (Wan, Tan , \& Mohammad , 2013) or they can seek for employment in other organizations. In the following sections, the link between the two theories to study are discussed.

\subsubsection{Fredrick Herzberg's Two Factor Theory}

Fredrick Herzberg proposed this hypothesis in 1959, based on feedback from engineers and accountants in the United States about their personal sentiments about their work environment (Stephen, 2009). According to the twofactor hypothesis, certain variables in the workplace contribute to job happiness, while others contribute to job discontent (Vijayakumar \& Saxena, 2015). These two sets of factors are categorized as hygiene and motivational Factors respectively. In this regard employees, remain in their current jobs because their needs are being met; when their needs are not met, then they are persuaded to leave resulting to higher labor turnover. According to the theory, employees are motivated by aspects which are related to the work itself (Rafikul \& Ahmad , 2008). The factors which motivate employees are referred to as the intrinsic factors or satisfiers and include recognition, achievement, advancement, responsibility, interesting work as well as growth. When the satisfiers are present at the 
workplace, employees are happy with their job. According to Nurun, Monirul, Abdullah, and Abdullah (2017) when employers meet the satisfaction of employees, they (employees) to have accomplished something, valued and consequently are willing to invest more efforts in their job. This made the two-factor theory relevant in this study since the first objective was set out to investigate how training and development strategies impact performance of officers in the National Police Service. Policer officers would consider any training and development programmes by the employer as achievement and advancement, which are part of the intrinsic factors in Herzberg's two-factor theory. Furthermore, the theory is important to the study since the second goal was to determine how career development methods impact police officer productivity in the NPS. Like Marciano , (2010); Ryan and Deci, (2000) observe, "motivation is considered to be the driving force behind an individual engaging in any activity" and in this regard, career advancement can be considered as an intrinsic motivation for police officers in the NPS.

The factors which cause workers not to be happy with their work are called hygiene factors or dissatisfiers. Some of the hygiene factors include supervision, company policy, interpersonal relationships, security, status, salary as well as working conditions. When the hygiene factors such as unfair organization policies and poor supervision are present at workplace, the employees are dissatisfied and tend to have negative attitude towards the organization. This however means that the employees are dissatisfied but does not imply they are satisfied. The theory indicates that the opposite of satisfiers is not dissatisfiers. Dissatisfiers differ with the satisfiers in that unlike satisfiers, they are not derived from the job itself but from external environment (Armstrong, 2007).

The presence or absence of either satisfiers or disatisfier highly informs the decision of employees to either exit or to remain in an organization. For an organization to retain its employees, it should develop strategies which ensure that employees remain motivated (James \& Mathew, 2012). Organizations which pay well and offer good benefits attract more and skilled employees who eventually translate to increased efficiency in production. This makes it possible to achieve higher competitive advantage and be flexible while still remaining competitive and cost effective. NPS require strategies which motivate employees to continue working and remain loyal to the Police Service as opposed to exiting in search of better jobs. The reduction in worker turnover in the service would go a long way.

\subsubsection{Job Embeddedness Theories}

According to Silbert (2005), people stay in their jobs if there are compelling factors from the organization or the community where they work which match their requirements and address their needs. Job embeddedness informs the choice of whether to exit or remain in the organization. Those who are invested in their work are more likely to stay with the company for a longer period of time, resulting in increased productivity as employees gain experience and the company avoids the expense of frequent recruiting. Professional and social connections that employees develop while working in a given organization become much entrenched in their lives to an extent that many of them would not be willing to break the web by exiting the organization. Organizations should endeavor to see their employees develop such deep relationship within the organization or in the surrounding community which will embed the employee to the organization such that their urge to exit is tremendously reduced. Embeddedness can be achieved through the components of job embeddness which include links, fit and sacrifice.

Links dimension refers to the attachments and relationships that an employee has within the organization or the nearby community. Links can include how the employees relate with colleagues at work, working teams, existence of child care and medical cover among others things. Employers should manage the links of their employees by for example, striving to have good working relationship, offering them with mentors, offering good medical cover and designing of work in teams. An employee who is well embedded within the organization and with the community may find it difficult to leave since they do not want the links to break.

Fit is the second component of job embeddedness and entails the extent to which workers aspirations match those of the organization or the community they serve. It is about whether the employee is comfortable with the values, cultures, weather, vision, policies or other issues that the organization or the community hold dear. The more employees' values and other aspects match with those of the organization, the more the employee is likely to remain in the organization. Hence, the human resource department within the NPS must ensure that the needs of the individual such as personal values, The career objectives and plans for the years to come suit the organization's objectives and plans. This will make sure that the police officers feel bonded to the NPS hence ensuring that the officers are retained and thereby promoting exemplary performance in service delivery.

The third approach in the theory of job embeddedness is sacrifice. Sacrifices refer to the benefits and privileges that an employee would forego in case they exit the organization. Such benefits include health benefits, convenience of work station from home, physical and job security. If the sacrifice is significant enough to the employees, it can persuade their choice to remain in the organization. Job embeddedness in NPS needs to be interrogated since it may provide possible solutions to retention of staff in the service. This is because it seeks to enable the NPS to ascertain why police officers decide to stay hence creating the most relevant strategies for retention that befits the NPS. 


\subsection{Research Methodology}

The study adopted a mixed methods approach by combining cross-sectional survey and phenomenology design. The mixed methods approach promotes the systematic combination of quantitative and qualitative data in a single study (Creswell \& Plano , 2011). According to Wisdom and Creswell (2013), this approach allows the researcher to collaborate data in a better way than when separate quantitative and qualitative data collection and analysis are carried out.

This study was conducted within Kisumu County. According to 2009 National Census the county has a population of about 968,909 . Kisumu County is $2085.9 \mathrm{~km}^{2}$. Siaya County to the west, Vihiga County to the north, Nandi County to the north east, and Kericho County to the east are the counties that border Kisumu County. In addition, Homa Bay County is to the south west, while Nyamira County is to the south. Kisumu County is split into seven Sub-Counties: Kisumu East, Kisumu Central, Kisumu West, Seme, Nyakach, Muhoroni, and Nyando. Kisumu County is split into seven Sub-Counties: Kisumu East, Kisumu Central, Kisumu West, Seme, Nyakach, Nyando and Muhoroni. The county is under the command of the County Commander with assistance of seven Sub-County Commanders commonly referred to as the OCPD. The Police Stations within the various Sub-Counties are under the command of station commanders or the OCS. Provision of service delivery by police officers in Kenya is affected by several factors such as availability of resources like such as communication equipment, vehicles and housing. According to Transparency International (2016) Nairobi and Kisumu had a higher rate of reporting on factors that affect service delivery by officers.

The study's target group included both active officers and officers who have left the force to pursue other opportunities. They shall police officers across the ranks ranging from gazetted officers to police constables within the police commands in Kisumu County as well as those who have left the service. A random sample of 385 police officers in the target population were selected to participate in this study. In addition, 20 police officer were selected purposely from among those who have resigned from service to join other employment sectors. Study participants were selected through probability proportional to size (PPS) sampling. Probability proportional to size sampling was appropriate since the population of police officers in Kisumu County is finite and therefore the probability of selecting a unit is proportional to its size.

Structured questionnaires were utilized to affirm that every respondent reply to the similar set of closed and open-ended questions preferred due to simplicity in the administration, scoring of analysis and items.Interview guides were used to obtain information from station commanders commonly referred to as OCS (6), Sub-County Police commander commonly referred to as OCPD (1), and Sub-County commissioners (3) as well the SubCounty Criminal Investigation Officer (SCCIO) formerly known as the DCIO.

A pilot research was carried out to see if the data obtained satisfied the research's goals. Thirty-nine volunteers were recruited from Gem Sub-County in Siaya County, and they were police officers in the grades of corporal and constable. According to Hertzog (2008), for the study a pilot sample is expected to represent $10 \%$ of the final sample size. The data was evaluated to find any problems in the questionnaire so that it could be revised accordingly. The study employed methodological triangulation with many data gathering methods to verify that the results were legitimate (Cohen, Morrison, \& Manion, 2007). This was beneficial since it allowed more complete data to be collected and confirmed results, which in the end became more effective.

Kothari (2004) alludes to the fact that analysis of data refers to ordering, categorizing, summarizing and manipulating of data in order to acquire answers to the questions of the research. The aim of the analysis is to acquire the meaning from the data collected. Inferential and descriptive statistics were applied to describe the basic features of the study data; this included using of percentages, frequency tables to determine the relationships or nexus between the various variables and determine the connection between various variables. In order to arrange, summarize and convey distribution of important variables, quantitative data were examined through descriptive statistics. The employed statistics were percentages, distributions of frequencies and contingency tables. In order to establish the diverse patterns, the initial stage of the quantitative data analysis was to calculate frequencies for respondents' background and personal characteristics. This enabled the aims of the study to be met. Data analysis was undertaken using the Statistical Package for the Social Sciences (SPSS) version 23 for Windows. All statistical measurements were conducted within $95 \%$ confidence interval.

\subsection{Findings}

1.8.1 Reliability Analysis

Table 1 Reliability Coefficients

\begin{tabular}{lcc}
\hline Scale & Cronbach's Alpha & Number of items \\
\hline Training and Development & 0.738 & 12 \\
Career Advancement & 0.731 & 11 \\
Compensation Strategies & 0.864 & 16 \\
Leadership Strategies & 0.796 & 15 \\
\hline
\end{tabular}

Reliability of the questionnaire was carried out through Cronbach's Alpha which measure draws 
measurement for the internal consistency. Cronbach's alpha was carried out by utilization of SPSS for the purpose of reliability analysis. The alpha coefficient value ranges between $0-1$ and may be utilised in describing the reliability of variables extracted from multi-point or dichotomous formatted scales or questionnaires. A greater value indicates a more reliable scale generated. Cooper \& Schindler (2003) note that 0.7 to be reliable and acceptable coefficient. Table above indicates that the compensation strategies had the greatest reliability $(\alpha=0.864)$ followed by leadership strategies $(\alpha=0.796)$, training and development $(\alpha=0.738)$ and finally career advancement $(\alpha=0.731)$. This shows that all the four scales are reliable as their values of reliability exceed the 0.7 recommended thresholds.

\subsubsection{Validity Analysis}

Balta (2008) cited that validity refers to the degree to which the instrument of research correctly measures what it basically ought to measure. Validity is associated with whether the findings are really about what they seem to be. Hair et al. (2007) noted that content validity should be basically established prior to any testing of a theory. Within the context of the current study, the responses were analyzed through calculating of representation percentages utilizing the content formula validity by Amin (2005). The formula is:

Content Validity Index $=\underline{\text { No. of Correct items valid }}=0.79$ and above

\section{Total no. of items}

Amin (2005) recommended CVI of about 0.79 or slightly higher and three or more experts may be regarded as evidence of good content validity.

\subsubsection{Demographic Information}

The study sought to determine the demographic characteristics of the respondents who took part in the study. The demographic characteristics sought were gender, rank, and length of service and highest education level attained. The response rate was also given to show the number of questionnaires that were returned. The demographic findings are presented in 4.2.1 to 4.2.5.

\subsubsection{Response Rate}

The number of questionnaires issued were 148 while 108 were returned complete for analysis, accounting for a response rate of 73 percent. Mugenda and Mugenda (2003) noted that a 50\% response rate is regarded to be good for any data analysis while any which is greater than 70\% is regarded to be very good. Orodho (2009) supports this by noting that any response rate which is above $50 \%$ leads to collecting of adequate data which may be generalized to mark the respondents' opinions over the problem of the study within the population targeted. Conversely, Kothari (2004) denoted that for a social science study, 60\% response rate is considered to be adequate for statistical analysis. Anchored on the views of Oloyo (2001), a good rate of response for a study is paramount since it mirrors the suitability of the procedure of a study. $73 \%$ response rate is hence a good response rate for data analysis in this study. The findings are presented in Table 2.

Table 2: Questionnaire Response Rate

\begin{tabular}{lcc}
\hline Response & Frequency & Percentage \\
\hline Returned questionnaires & 108 & $73 \%$ \\
Un-returned questionnaires & 40 & $27 \%$ \\
\hline Total & $\mathbf{1 4 8}$ & $\mathbf{1 0 0}$ \\
\hline
\end{tabular}

\subsubsection{Gender of Respondents}

The goal of the study was to determine how respondents were classified in terms of gender. The results as depicted in Table 3 indicate that $35.19 \%$ of the total respondents were female whereas their male counterparts were $64.81 \%$ suggesting that the majority of the respondents were male. The response on gender was vital since both men and women in uniform play different roles when it comes to law enforcement and might be having different perception when it comes to retention within the National Police Service.

Table 3: Gender of Respondents

\begin{tabular}{lcc}
\hline Response & Frequency & Percentage \\
\hline Male & 70 & 64.81 \\
Female & 38 & 35.19 \\
\hline Total & 108 & 100 \\
\hline $\mathbf{1 . 8 . 6}$ Length of Service & \\
Concerning the period served in the service, the results as given in figure 1 indicate that for less than 5 years 16.2 \\
per cent of the interviewees have had a service, whereas for 6-10 years 24.3 percent had a service. For 11-15 \\
years 10.8\% of respondents served, while those served after 15 years served were 48.6\%. This is crucial in \\
understanding how work experience among the law enforcement agents could affect the retention rates.
\end{tabular}




\section{Figure 4.1:}

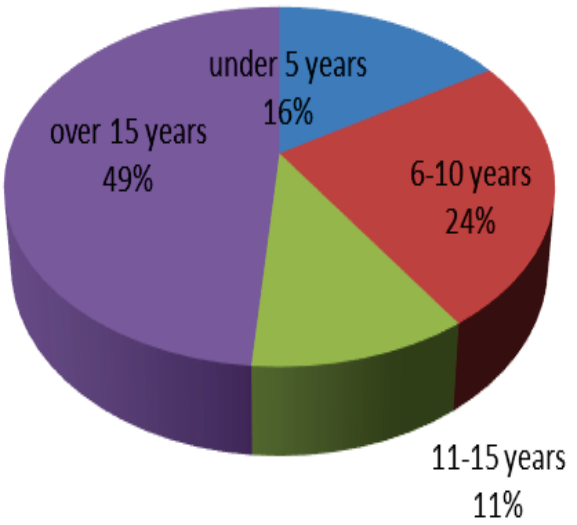

\section{Figure 1: Length of Service}

\subsubsection{Rank of Respondents}

An analysis of the ranks of the officers was made and the results obtained are shown in Table 4. The analysis in Table 4 indicates that majority of the respondents (37\%) were police constables, $28 \%$ of the respondents were police corporals, $14 \%$ of the respondents were sergeants, $9 \%$ were senior sergeants, $7 \%$ were police inspectors while $5 \%$ of the respondents were chief inspectors. In this study rank was paramount in undemanding the various strains which the officers undergo and whether rank affected their performance since some of the officers had served for long without any promotions. The study noted that graduate police constables who had served for long without any promotions or proper remunerations were contemplating exiting the service for greener pastures.

Table 4 : Rank of Respondents

\begin{tabular}{lcc}
\hline Response & Frequency & Percentage (\%) \\
\hline Police Constables & 40 & 37 \\
Corporals & 30 & 28 \\
Sergeant & 15 & 14 \\
Senior sergeant & 10 & 9 \\
Inspectors & 8 & 7 \\
Chief insepctors & 5 & 5 \\
\hline Total & $\mathbf{1 0 8}$ & $\mathbf{1 0 0}$ \\
\hline
\end{tabular}

This study was dominated by male respondents. The response on gender was vital since both men and women in uniform play different roles when it comes to law enforcement and might be having different perception when it comes to retention within the National Police Service. The results reveal that the majority of respondents serving in the military have been been in the military for more than 15 years. This is crucial in understanding how work experience among the law enforcement agents could affect the retention rates and whether the police are contented with what they receive from the service.

In relation to ranks, this study was dominated by police constables. It is paramount to note that rank was paramount in undemanding the various strains which the officers undergo and whether rank affected their performance since some of the officers had served for long without any promotions. The study noted that graduate police constables who had served for long without any promotions or proper remunerations were contemplating exiting the service for greener pastures. Finally, in terms of educational attainment, according to the researchers, the researcher intended the majority of those interviewed to have high school education. The overwhelming majority of respondents (64 per cent) have finished high-school education according to statistics provided in Figure 2. The justification for the study being dominated by those having secondary level of education is due to the fact that the minimal entry into the service is form four $\mathrm{D}+$ grade

\subsubsection{Respondent's Level of Education}

The scientist wanted to discover how well the participants were trained. The overwhelming majority of respondents (64 per cent) have finished high-school education according to statistics provided in Figure 2. Additionally, 20(19\%) of the respondents had diploma level of education, 12(11\%) were bachelor's degree holders while $6(6 \%)$ of the respondents had acquired master's degree in various disciplines. The justification for the study being dominated by those having secondary level of education is due to the fact that the minimal entry into the service is form four D+ grade. Further the study realized that those who were having tertiary education, had acquired such education in disciplines such as; criminology, security, diplomacy, international relations, 
development studies, forensic science, peace and conflict management. It was also encouraging to learn that some officers' particularly gazetted officers were pursuing doctorate studies.

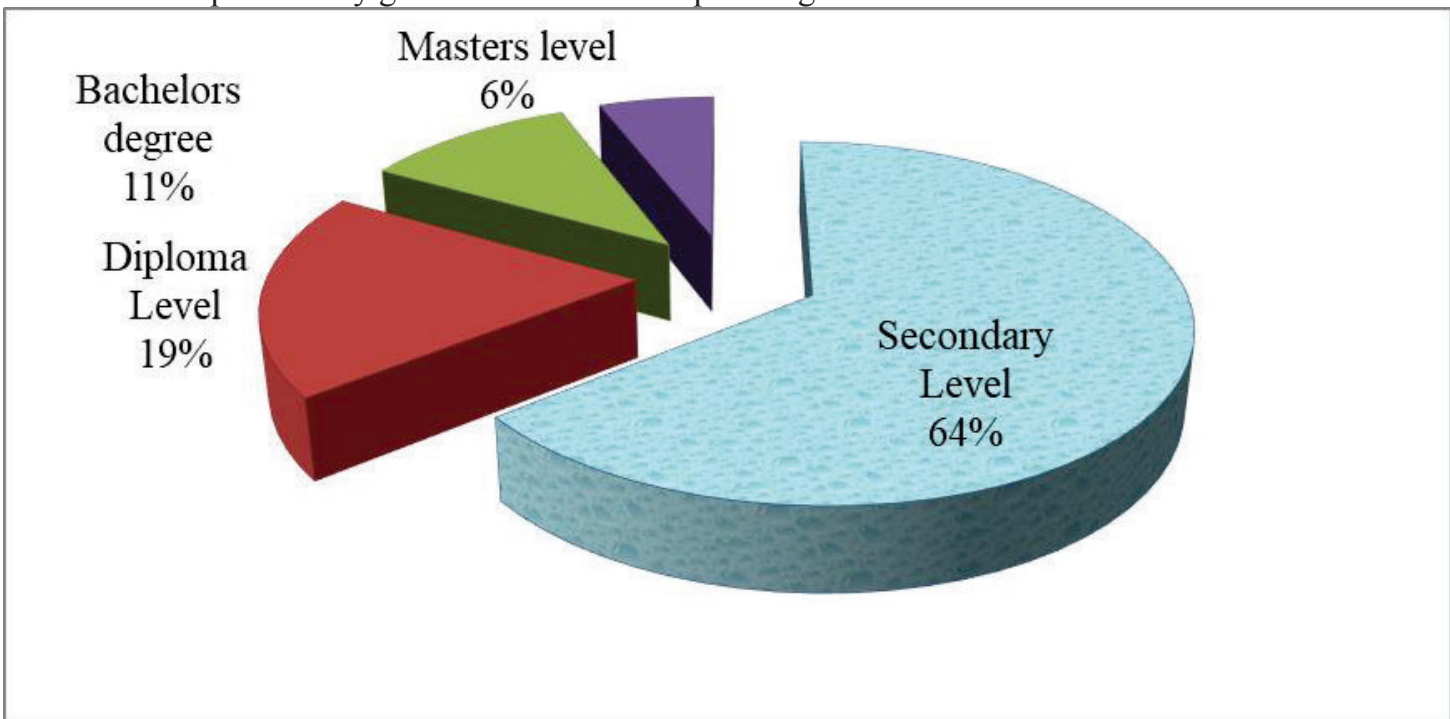

Figure 2: Level of education of Respondents

\subsubsection{Whether Training and Development affects Police Performance}

One of the main interests of the first specific objective was to determine whether training and development affects performance of police officers within the National Police Service. This study noted that majority of the respondents $(83.3 \%)$ agreed that training and development strategies as a retention strategy impacted performance of police officers within the NPS significantly. Conversely, 16.7 of the respondents cited that training and development retention strategies had no effect on police performance.

The findings are in line with Birzer (2003) who noted that training is crucial in most sections of the police service though the environment today seems to be debatable. Training boosts the skills and capacity of the police and increases the chances of the officer winning the confrontations, which in turn reduces complaints and lawsuits against the department or individual police officer. Community also gains more confidence with the police service when officers undergo trainings. The findings are presented in Table 5.

Table 5: Whether Training and Development affects Police Performance

\begin{tabular}{lcc}
\hline Response & Frequency & Percentage (\%) \\
\hline Yes & 90 & 83.3 \\
No & 18 & 16.7 \\
\hline Total & $\mathbf{1 0 8}$ & $\mathbf{1 0 0}$
\end{tabular}

Findings from the key informant interview by one of the senior Gazetted officers from Nyando area indicated that;

Training and development is a serious challenge within the National Police Service. Oblivious of the reforms and milestones made in a bid to improve the image of the NPS and its service delivery, training and development in areas such as career counseling and coaching is a major challenge. Programs such as inter-agency coordination among various security agents such as the NIS among other state security agencies is vital in career development among the law enforcement agents (Source:

Key Informant Interview 1, 4/08/2020)

1.8.10 Extent of Effect of Training and Development on Police Performance

According to the findings presented in Figure 3, the study noted that training and development strategies was very paramount in improving the performance of police officers as indicated by $51 \%$ of the respondents who noted to a great extent. Moreover, 40(37\%) of the respondents cited very great extent, 5\% cited moderate extent while $4 \%$ of the respondents cited little extent and no extent subsequently. The findings are consistent with Ransley's Task Force (2009) which reported that training and development was very paramount in improving service delivery within the NPS and public appeal. The Task further noted that although the senior officers have been receiving reasonably good and frequent training, this has not been replicated to the lower cadre of officers. 


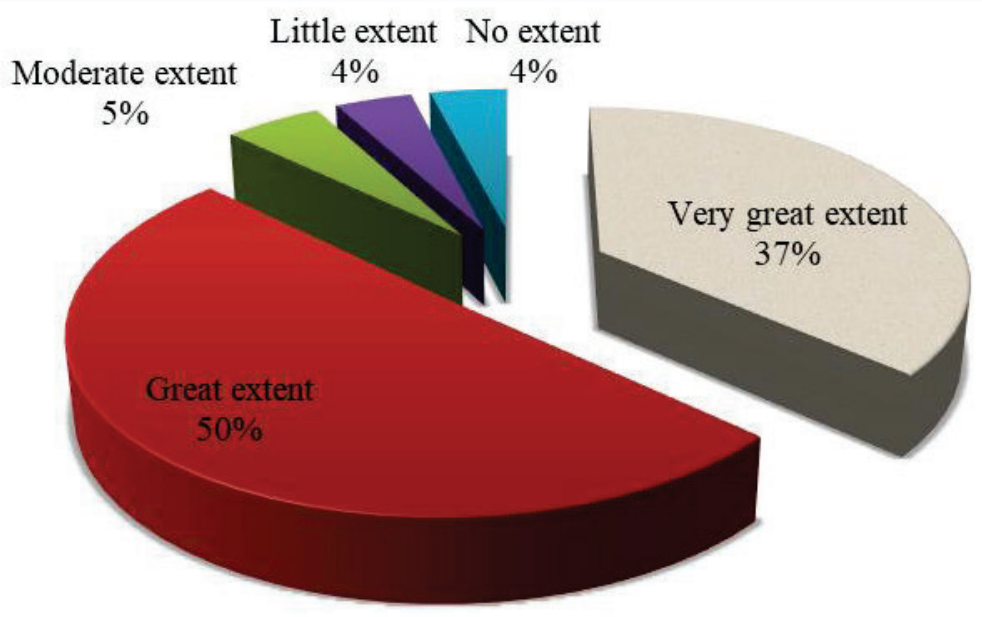

Figure 3: Effect of Training and Development on Police Performance

According to One Chief inspector who serves as OCS from Kisumu Central he cited during an interview that;

There is a strong nexus between training and development as a retention strategy and ensuring that the performance of police officers is upheld. Majority of the officers will feel motivated if well trained through various short courses and career vocation trips for the purpose of benchmarking. Although the NPS has been taking some of its officers to developed countries such as China for benchmarking exercises, the trickle effect of such career development initiatives is yet to be realized within the entire service (Source: Key Informant Interview 2, 3/08/2020).

1.8.11 Extent of Agreement levels on Training and Development on Performance of Police

In regard to the level on agreement on a Likert scale where (1. Strongly disagree 2. Disagree3. Not sure 4. Agree 5. Strongly agree) the study reported that majority of the respondents (35\%) indicated that agree that the NPS has a comprehensive policy on training and development which has greatly improved its performance and service delivery in general. Conversely, $27 \%$ of the respondents cited that they strongly disagree and strongly agree subsequently.

Interestingly, the majority of respondents $(50 \%)$ strongly disagree that the NPS conducts continual training needs assessments to improve performance. On the other hand, $32 \%$ of the respondents disagree. The survey also found that a large percentage of responders $(40 \%)$ said that training programs are reviewed to see how effective they are at enhancing officer performance within the NPS. Furthermore, the majority of respondents (40 percent) agreed that information gained via ongoing training had a direct impact on my work performance as a police officer, according to the survey. As a result, $35 \%$ of the respondents strongly agreed.

The study noted that a greater percentage of the respondents (42\%) indicated that they strongly disagree that the current police-training curriculum is adequate for improving performance. Additionally, $28 \%$ of the respondents disagreed. According to $37 \%$ of the respondents cited that they strongly disagree that the NPS has adequate training facilities as well as equipment for improving of police performance within the NPS. Conversely, $33 \%$ of the respondents also agreed.

Concerning whether on-job training at the NPS and whether it is adequately done, the study noted that majority of the respondents (32\%) indicated that they disagree that on-job training is adequately conducted, followed by $30 \%$ of the respondents who strongly disagreed. Among the concerns of the first objective was also on the issue of upgrading facilities at the police training colleges to improve on police performance. Majority of the respondents $(45 \%)$ that there is an urgent need of improving the conditions of police training facilities to better their performance. Conversely, $35 \%$ of the respondents also agreed. 
performance of the police is improved and avert any possible turnover.

\subsection{Recommendations}

In order to ensure that police performance is enhanced through good retention strategies, the study recommends that the oversight committees charged with the mandate of steering police reforms within the country need to initiate an organizational culture which is driven by change; this will assist in accommodating the leadership dynamicity challenges which depress the general police reforms

There is a need of ensuring that organizational learning in police services and particularly to the junior officers who even after serving for a longer duration still need improving of their education. This will assist in raising their level of understanding, expertise and particularly in problem solving which ultimately will raise service quality and performance of the police.

There is a need on setting up an independent committee in assessing the effectiveness of the current career advancement, leadership plans, compensation strategies and other retention strategies. This should be carried out in a view of evaluating the weaknesses as well as proposing mitigation strategies for high labour turnover within the service. Police should be trained in Public relation programmes and community approaches such as Nyumba Kumi initiative in order to improve their interpersonal skills and community engagement with an aim of boosting their performance.

\section{References}

Amnesty International. (2013). Police reforms in Kenya a Drop in the Ocean. AI Publications. London, UK: Amnesty International press.

Bartlett, J. E., Kotrlik, J. W., \& Higgins, C. C. (2001). Organizational research: Determining appropriate sample size in survey research. Information Technology, Learning, and Performance Journal, 19(1).

Birzer, M. (2003). The Theory of Andragogy Applied to Police Training. Policing, 26, 29 - 42.

Cho, E. (2016). Making reliability reliable: A systematic approach to reliability coefficients. Organizational Research Methods, 19(4), 651 - 682.

Cohen, J. (1988). Statisitcal power and analysis for the behavioural sciences (2nd ed.). Hillside, N.J: Lawrence Erlaum Associates, Inc.

Creswell , J. W., \& Plano, C. V. (2011). Designing and conducting mixed methods research (2nd ed.). Thousand Oaks, CA:: Sage.

Feldman, D. (2000). The Dilbert syndrome: How employee cynicism about ineffective management is changing the nature of careers in organizations. American Behavioral Scientist, 43, 1286 - 1301.

Field, A. (2009). Discovering statistics using SPSS. London: SAGE Publications Ltd.

Fileding, J., \& Gilbert, N. (2006). Understanding social statistics. London: Sage Publications Ltd.

Fox , D., Byrne, V., \& Roualt, F. (2009). Performance improvement: what to keep in mind. Training and Development, 53(8), 895-915.

Greenhaus, J. H. (2004). Breaking all the rules for recruitment and retention. Journal of career planning and employment, 6(13), 6 - 8 .

Hertzog, M. A. (2008). Considerations in determining sample size for pilot studies. Research in Nursing \& Health, 31(2), 180-91.

Hessler, R. M. (1992). Social Research Methods. West Publishing Company.

Jagero , N., Komba, V., \& Mlingi, M. (2012). Relationship between On-the-Job Training and Employees’ Performance in Courier Companies in Dar es Salaam, Tanzania.International . Journal of Humanities and Social Sciences, 2(22), 114 - 120

James , L., \& Mathew, L. (2012). Employee Retention Strategies: IT Industry. SCMS Journal of Indian Management, 9(3).

Khokhar, Z., Laghari, I., \& Lakhani , M. Q. (2019). Factors affecting customer loyalty in banking sector of Hyderabad, Pakistan: A study on conventional and Islamic banking. South Asian Journal of Social Studies and Economics, 1 - 16.

Kothari, C. R. (2004). Research methodology: Methods and techniques. New Age International.

Marciano, P. (2010). Carrots and sticks don't work: Build a culture of employee engagement with the principles of RESPECT. New York: McGraw-Hill.

Mellahi, K., \& Collings, D. G. (2010). The barriers to effective global talent management: The example of corporateelites in MNEs. Journal of World Business, 45(2), 143 - 149.

Mendez, T. M., \& Stander, K. (2011). Positive Organisation. The role of leader Behavior in work engagement and Retention. South African Journal of Industrial Psychology,(37)1., 37(1).

Ngari, M. (2015). nfluence of Training on Employee Performance: A Case of Judiciary's Lower Courts in Kenya . Unpublished Master's Thesis; University of Nairobi.

Njuguna, N. (2013). Police Reforms in Kenya: Perception and Expectations of Key Stakeholders. Nairobi: IPAR 
Discussion Paper No.116/2013.

Saraswathi , S. (2011). A Study on Factors that Motivate IT and Non-IT Sector Employees: A Comparison. International Journal of Research in Computer Application and Management, 1(2), 72 - 77.

Stephen, P. R. (2009). Organizational Behaviour: International Version. 13/E. Pearson Higher Education.

Tahir, A., \& Sajjad, S. (2013). Assessing the Impact of Training on Employees' Performance in Commercial Banks in Urban Lahore. The Lahore Journal of Business, 2(1), 95 - 109.

Transparency International. (2016). Kenya Police service satisfaction survey and needs analysis report, 2016: A focus on Kisumu and Nairobi counties. Nairobi: Transparency International.

Trochim, M. W., \& James , P. D. (2008). Research methods knowledge base (3rd ed.). Mason, OH: Thomson Custom Pub.

Vijayakumar, V. S., \& Saxena, U. (2015). Herzberg revisited: Dimensionality and structural invariance of Herzberg's two factor model. Journal of the Indian Academy of Applied Psychology, 41, 291 - 298. 